\title{
Population Sequencing
}

National Cancer Institute

\section{Source}

National Cancer Institute. Population Sequencing. NCI Thesaurus. Code C135457.

A process by which the individual genomes of most or all of an entire population of a species undergoes a large-scale comparison of the DNA sequences within that population, using probabilistic matching tools. Such comparison allows for the study of microevolution within a population. 